\title{
- Citologia conjuntival por impressão em gatos (Felis domestica)
}

- Conjunctival impression cytology in cats (Felis domestica)

\section{- Citología conjuntival por impresión en gatos ( domestica)}

* Claudia Valéria Seullner Brandão ${ }^{1}$ - CRMV-SP-n ${ }^{0} 6325$

Bruno Watanabe Minto ${ }^{2}$

Noeme Sousa Rocha ${ }^{3}$ - CRMV-SP - n 5869

José Joaquin Titton Ranzani ${ }^{1}$ - CRMV-SP-n ${ }^{0} 1482$

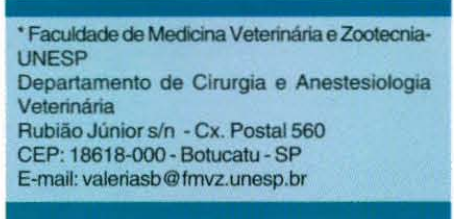

1 Docentes do Departamento de Cirurgia e Anestesiologia Veterinária - FMVZ-UNESP/Botucatu.

Acadêmico do $5^{\circ}$ ano de Medicina Veterinária - FMVZ - UNESP/Botucatu.

3 Docente do Departamento de Clínica Veterinária - Anatomia Patológica - FMVZ - UNESP/Botucatu.

\section{RESUMO}

A citologia conjuntival é um importante método diagnóstico, podendo ser facilmente realizada pelo clínico veterinário. O presente trabalho teve como objetivo o estudo da viabilidade do exame citológico da mucosa conjuntival pelo método de impressão em papel-filtro, assim como estabelecer o padrão normal nos felinos domésticos. Realizou-se o exame citológico da mucosa conjuntival pelo método de impressão em papel-filtro de 30 animais da espécie felina, sem utilização da anestesia tópica. As técnicas de colorações utilizadas foram o Giemsa e o Shorr. O padrão normal foi caracterizado por predominância da disposição em agrupamentos celulares e células das camadas intermediárias e superficiais. A técnica de colheita de material mostrou-se prática, rápida e proporcionou a obtenção de um material de boa qualidade. O método de impressão utilizado não se mostrou traumático à conjuntiva, amenizando a dificuldade encontrada na manipulação dos animais da espécie felina, caracterizando-se como um importante exame complementar no diagnóstico e direcionamento terapêutico de afecções oculares externas.

Palavras-chave: Citologia. Conjuntiva. Gatos. Impressão. 


\section{INTRODUÇÃO}

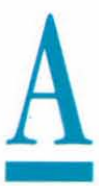

citologia conjuntival é um importante método diagnóstico e auxiliar no direcionamento terapêutico das enfermidades oculares externas. $\mathrm{O}$ procedimento para a realização do exame citológico da mucosa conjuntival dos olhos humanos, bem como a sua interpretação está detalhadamente descrita (LAVACH et al., 1977). Entretanto, a literatura veterinária apresenta poucos trabalhos a respeito do exame citológico da mucosa conjuntival normal e inflamada dos felinos domésticos.

A citologia conjuntival, independente da espécie, pode ser facilmente realizada pelo clínico veterinário e fornece importantes informações para a confirmação da suspeita diagnóstica e instituição da terapia ocular mais adequada. Contudo, a interpretação do exame citológico da mucosa conjuntival alterada necessita de um padrão normal para que se possa efetuar a comparaçãoe, assim, estabelecer a presença ou não de uma alteração.

O presente trabalho teve como objetivo o estudo da viabilidade do exame citológico da mucosa conjuntival por impressão em papel-filtro, assim como estabelecer o padrão normal nos felinos domésticos, enfatizando a sua importância na orientação do diagnóstico das afecções conjuntivais.

\section{REVISÃO DA LITERATURA}

A mucosa conjuntival é formada por um epitélio colunar pseudo-estratificado e células de "goblet" ou caliciformes (BAKER; LUMSDEN, 2000). Esse epitélio caracteriza-se por ser descamativo ou esfoliativo e pela ausência de queratinização (AZEVEDO, 1962). É composto basicamente por três camadas celulares: uma camada de células cubóides no estrato basal, as células poliédricas ou intermediárias e uma camada superficial composta de células colunares. As células de "goblet" ou caliciformes estão distribuídas especialmente na conjuntiva do fórnix (JÉGOU; LIOTET, 1993).

Em virtude docontatocom um meiopotencialmente contaminante, a presença de linfócitos e plasmócitos no tecido submucoso é observada na conjuntiva (AZEVEDO, 1962; JÉGOU; LIOTET, 1993), especialmente na região de fórnix (BAKER; LUMSDEN, 2000), sendo comum o achado de linfócitos em exames citológicos de conjuntivas normais (AZEVEDO, 1962).

A citologia dos olhos normais de caninos e felinos domésticos caracteriza-se pela presença de células epiteliais dispostas em "lâminas" (BANKS, 1992) ou "tapetes" (LAVACH et al., 1977; SLATTER, 1990).
As células podem apresentar-se como vários grupos celulares (AZEVEDO, 1962). As células epiteliais coradas pelo Giemsa apresentam um núcleo grande, arredondado, homogêneo e um citoplasma abundante (LAVACH et al, 1977; JÉGOU; LIOTET, 1993).

Não há diferenças significativas entre a qualidade do material obtido no método de raspado conjuntival em comparação com o método de citologia por impressão (THATCHER et al., 1977).

As impressões mais profundas contêm células basais e parabasais arredondadas, com citoplasma altamente basofílico e fortemente coradas. São menores quando comparadas às superficiais (BANKS, 1992; JÉGOU; LIOTET, 1993), sendo geralmente observadas, na lâmina, em grupos (AZEVEDO, 1962) e são encontradas em pequena quantidade no exame citológico da conjuntiva normal (LAVACH et al., 1977).

As células predominantes são as células das camadas intermediária e superficial. As células intermediárias apresentam formato arredondado ou poligonal e, geralmente, apresentam-se agrupadas ou em "lençol" (LAVACH et al., 1977; BANKS, 1992; JÉGOU; LIOTET, 1993). As células superficiais são achatadas e grandes, possuindo núcleo central e redondo, e citoplasma pouco corado e acidófilo (AZEVEDO, 1962; LAVACH et al., 1977; BANKS, 1992; JÉGOU; LIOTET, 1993); essas células sempre ocorrem isoladas (AZEVEDO, 1962). Células queratinizadas raramente são encontradas (LAVACH et al., 1977; BANKS, 1992).

Grânulos de melanina no citoplasma das células epiteliais superficiais são freqüentemente observados (LAVACH et al., 1977; GELATT, 1991; BANKS, 1992; JÉGOU; LIOTET, 1993; BAKER; LUMSDEN, 2000) e podem estar disseminados por todo citoplasma ou concentrados ao redor do núcleo (JÉGOU; LIOTET, 1993). Os grânulos de melanina podem ser encontrados nos espaços extracelulares (AZEVEDO, 1962). Utilizando-se coloração de Giemsa, os grânulos apresentam-se verde-escuros, marrons ou negros (BANKS, 1992; JÉGOU; LIOTET, 1993).

As células de "goblet" são observadas quando a coleta de material atinge o fórnix. Essas células são facilmente reconhecidas em razão de seu grande tamanho, núcleo deslocado para a periferia da célula e um ou mais grandes vacúolos no citoplasma; esses vacúolos contêm muco (LAVACH et al., 1977; BANKS, 1992; JÉGOU; LIOTET, 1993; BAKER; LUMSDEN, 2000) e são fracamente corados em azul ou não corados pelo método de Giemsa (LAVACH et al., 1977; BANKS, 1992). 
Alguns elementos não celulares podem ser observados no exame citológico da mucosa conjuntival normal dos animais, desde que em pequena quantidade; são representados por debris de elementos queratinizados como a descamação de pêlos, cílios, fibrina e muco (JÉGOU; LIOTET, 1993).

A presença de bactérias, na superfície ou dentro das células epiteliais, pode ser observada ocasionalmente, sendo considerada normal na ausência de outros sinais de doença (LAVACH et al., 1977).

Linfócitos, monócitos e neutrófilos raramente são encontrados no exame citológico da mucosa conjuntival do olho normal (LAVACH et al., 1977; BANKS, 1992; JÉGOU; LIOTET, 1993).

Corpos de inclusão citoplasmáticos não são encontrados, porém pseudoinclusões podem ser vistas como conseqüência da ruptura do núcleo durante a preparação da impressão (LAVACH et al., 1977; JÉGOU; LIOTET, 1993) e representam a herniação do conteúdo nuclear em direção ao citoplasma da célula (LAVACH et al., 1977).

\section{MATERIAL E MÉTODOS}

No presente estudo foram utilizados 30 animais da espécie felina (Felis domestica) $), 22$ fêmeas e 8 machos, dos quais 28 sem raça definida e dois pertencentes à raça siamesa. A idade dos animais variou de sete a 60 meses, média de 18,2 meses. Todos os animais eram sadios e sem alterações oftálmicas ao exame.

Os gatos foram submetidos ao exame citológico da mucosa conjuntival de ambos os olhos. Após eversão das margens palpebrais, as células foram obtidas pelo contatode papel-filtro ${ }^{1}$ com a mucosa conjuntival durante dois a quatro segundos (Figura 1). As coletas foram realizadas das mucosas conjuntivais inferior e superior, na regiãocentral.

O material coletado foi imediatamente impresso em lâmina de microscopia e, a seguir, corado pelos métodos de Giemsa e Shorr. As lâminas destinadas à coloração pelo método de Giemsa foram fixadas em Álcool Metílico P.A. e as coradas por Shorr, em Álcool Etílico absoluto P.A.

A seguir, as lâminas foram examinadas por meio de microscopia óptica. Os critérios utilizados para o estudo das lâminas foram: avaliação geral do conjunto, observando-se os valores qualitativos e quantitativos do material coletado; focalização dos pontos de maior concentração celular e análise detalhada dos caracteres morfológicos e quantitativos das células e elementos não celulares.

Figura 1. Procedimento de coleta do material com impressão do papel filtro após a eversão da pálpebra inferior.

\section{RESULTADOS}

O exame microscópico das lâminas coradas pelo Giemsa demonstrou células epiteliais adequadamente coradas, das quais a grande maioria apresentou núcleo acidófilo e citoplasma pouco ou levemente rosado (Figura 2).

A avaliação quantitativa das células epiteliais, realizada de forma sistemática, revelou, em média, 36,3 células epiteliais por campo microscópico examinado do olho esquerdo e 32,9 do olho direito.

Os tipos celulares mais freqüentemente encontrados foram as células das camadas intermediária e superficial (Figuras 3 e 4), que se apresentaram predominantemente agrupadas em $93,3 \%$ das lâminas, referentes ao olho esquerdo, e $99 \%$, ao olho direito (Figura 2); nas demais, houve predominância de células isoladas, em ambos os olhos. A grande maioria das células isoladas era do tipo superficial.

As células epiteliais conjuntivais intermediárias mostraram núcleo grande, circular ou oval e tamanho reduzido quando comparadas com as células mais superficiais. As células epiteliais superficiais possuíam formato poliédrico, citoplasma abundante e núcleo redondo, em posição central na célula. 
Brandão C. V. S.; Minto B. W.; Rocha N. S.; Ranzani J. J. T. - Citologia Conjuntival por impressão em gatos (Felis domestica) - Conjunctival impression cytology in cats (Felis domestica) - Citología conjuntival por impresión en gatos (Felis domestica) - Rev. educ. contin. CRMV-SP / Continuous Education Journal CRMV-SP. - São Paulo, volume 5, fascículo 1, p. $41-47,2002$

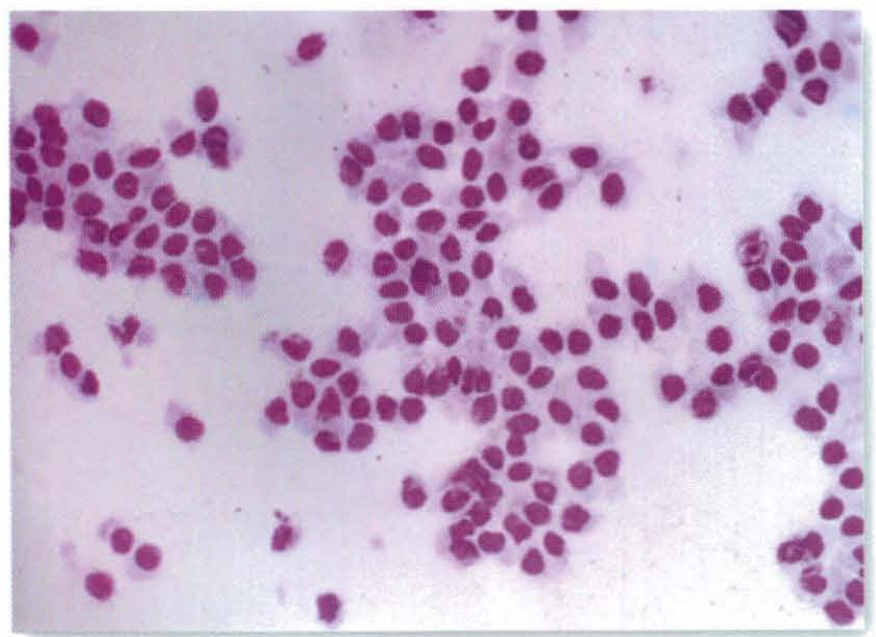

Figura 2. Fotomicrografia de células epiteliais conjuntivais dispostas em agrupamentos do tipo "tapete" (Giemsa, 400X).

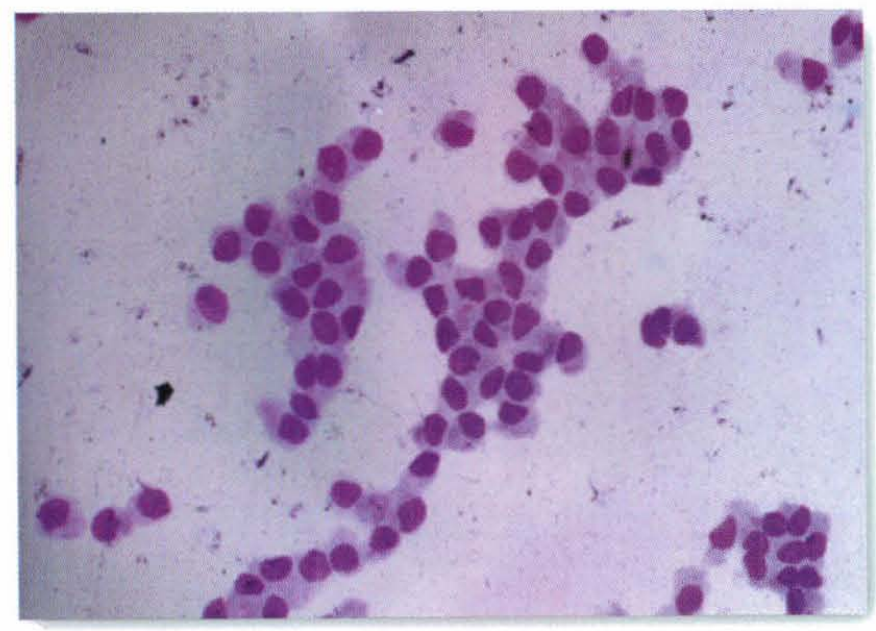

Figura 3. Fotomicrografia de células epiteliais conjuntivais intermediárias. Observar o núcleo grande e homogêneo (Giemsa, 400X).

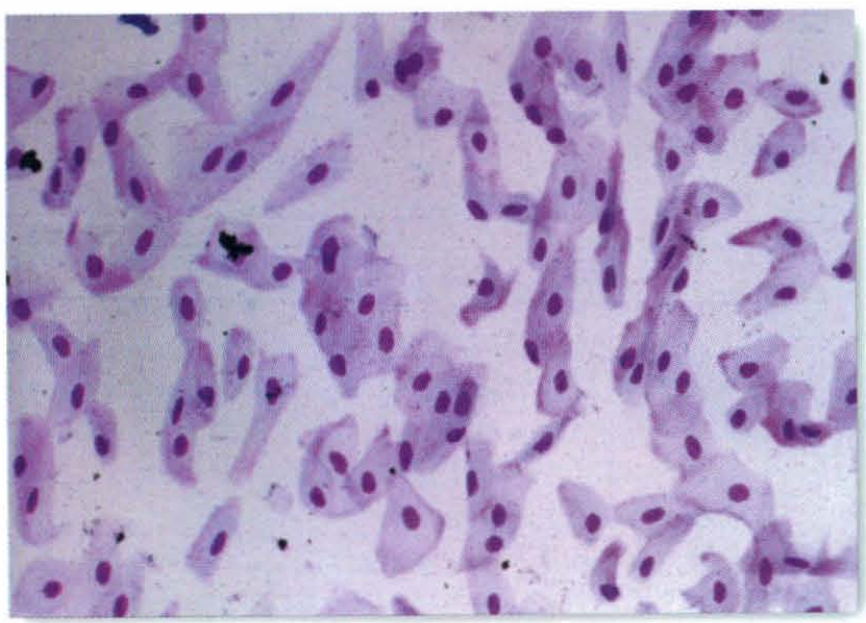

Figura 4. Fotomicrografia de células epiteliais conjuntivais superficiais. Observar o núcleo redondo e central com citoplasma abundante pouco corado (Giemsa, 400X).
A predominância da formação de diversos agrupamentos celulares foi observada com relação à disposição na forma de lençóis celulares em ambos os olhos.

Apenas cinco lâminas de diferentes animais apresentaram uma prevalência de células isoladas.

Grânulos de melanina, em graus variados de intensidade, foram observados em $93,3 \%$ dos animais (Figura 5), mas não raramente foram observados fora do citoplasma das células.

A presença de pequena quantidade de muco foi observada em poucas lâminas. Em $26,6 \%$ dos animais, notaram-se células queratinizadas em pequena quantidade (Figura 6). Células inflamatórias, como neutrófilos e linfócitos, raramente foram observadas. Em algumas impressões pôde-se notar a presença de células degeneradas ou em processo de degeneração e restos celulares. Inclusões celulares e células "goblet" não foram encontradas.

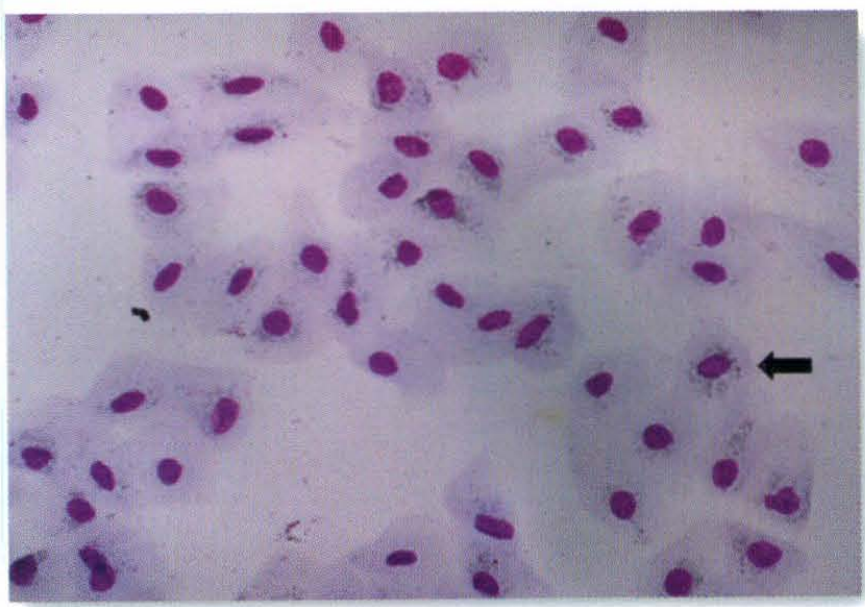

Figura 5. Fotomicrografia de células epiteliais conjuntivais superficiais. Observar a presença de grânulos de melanina (seta) no citoplasma (Giemsa, 400X).

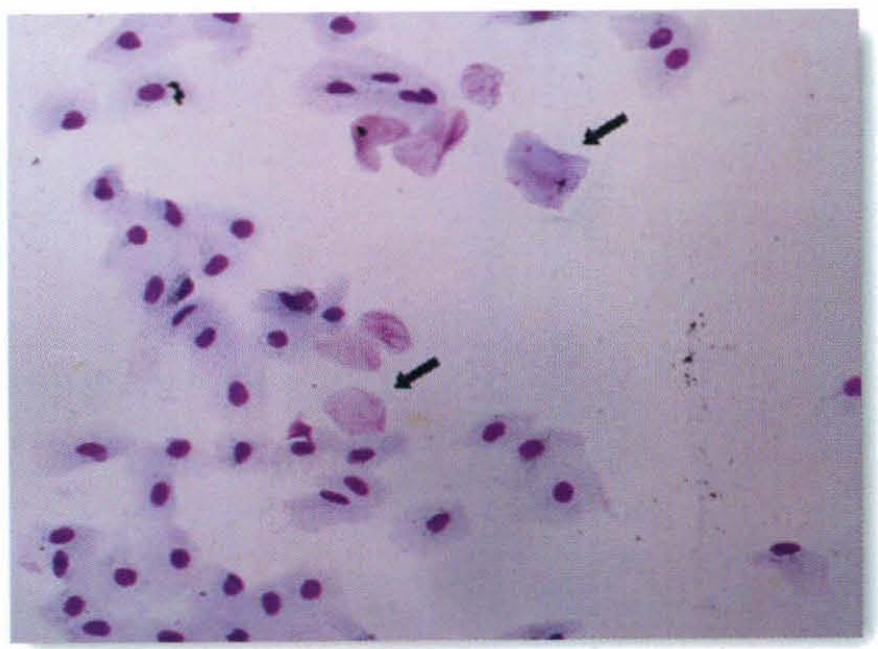

Figura 6. Fotomicrografia de células epiteliais conjuntivais queratinizadas (setas) e células superficiais. (Giemsa, 400X). 


\section{DISCUSSĀO}

A técnica de coleta do material mostrou-se prática e de fácil execução, necessitando apenas de uma boa contenção dos gatos para evitar traumatismos oculares. Os animais não apresentaram nenhum tipo de desconforto ou lesão associados à falta de utilização de procedimentos anestésicos, provavelmente pelo pouco tempo de contato do papel-filtro com a conjuntiva, 2 a 4 segundos, e rápida realização do procedimento.

$\mathrm{O}$ método de coleta por raspagem da mucosa conjuntival é mais traumático, causando um certo grau de desconforto ao animal (THATCHER et al., 1977; MALERBA, 1990), o que não foi observado utilizando-se o método de coleta por impressão.

A não utilização do colírio anestésico para proceder o exame eliminou os efeitos citotóxicos presentes quando de sua aplicação (MALERBA, 1990).

O material obtido foi rico e suficiente para a realização da avaliação preconizada. A técnica de coloração utilizada mostrou-se eficaz e satisfatória no que diz respeito à qualidade do material, sendo também facilmente realizada, rápida (trinta minutos) e sem necessidade de grande conhecimento técnico.

Em todos os animais submetidos ao exame citológico pelo método de impressão, observou-se a presença de células epiteliais conjuntivais. Esses achados são semelhantes aos descritos ao se utilizar a técnica de coleta por raspagem da mucosa conjuntival (MALERBA, 1990). Na grande maioria das lâminas foram observadas células epiteliais conjuntivais pertencentes às camadas intermediária e superficial do epitélio conjuntival. Os achados referentes à morfologia das células são compatíveis aos descritos na literatura (AZEVEDO, 1962; LAVACH, et al., 1977; MALERBA, 1990; JÉGOU; LIOTET, 1993).

As células epiteliais conjuntivais apresentaramse agrupadas ou formaram lençóis celulares e raramente predominou a presença de células isoladas, achados semelhantes aos descritos na literatura (AZEVEDO, 1962; LAVACH et al., 1977; MALERBA, 1990; JÉGOU; LIOTET, 1993). As células mais superficiais eram maiores, possuindo núcleo redondo e central com citoplasma abundante, acidófilo ou pouco corado pelo Giemsa. Muitas vezes, essas células apresentaram formato poliédrico com bordas do citoplasma reviradas, de acordo com o relatado por MALERBA (1990).

Células mais profundas como as basais não foram encontradas na maioria das impressões, demonstrando a vantagem do método de impressão por papel de filtro sobre o raspado conjuntival, caracterizando-se aquele como menos traumático à mucosa conjuntival. O método de coleta com papel-filtro apresenta ainda vantagens sobre o método de coleta por "swab", considerando que neste há perda de células que não são transferidas à lâmina (THATCHER et al., 1977).

Grânulos de melanina foram observados em 93,3 $\%$ dos animais, estando de acordo com o relatado na literatura (AZEVEDO, 1962; LAVACH, et al. 1977; BANKS, 1992; JÉGOU; LIOTET, 1993). Estes grânulos margeavam o núcleo na maioria das células epiteliais conjuntivais que os continham, porém também foram encontrados disseminados pelo citoplasma. Esses achados condizem com as descrições de Lavach et al. (1977), Malerba (1990), Jegou e Liotet (1993), Baker e Lumsden (2000).

Células de "goblet" não foram observadas em nosso estudo, bem como corpúsculos de inclusão (LAVACH et al., 1977; MALERBA, 1990; JÉGOU; LIOTET, 1993; BAKER; LUMSDEN, 2000).

Raros neutrófilos e linfócitos foram encontrados em $10 \%$ dos animais, de acordo com o observado por Lavach et al. (1977), Jegou e Liotet (1993) e Baker e Lumsden (2000), que os consideram como evento normal, desde que não estejam presentes outros sinais de doença ocular. A presença de outras células, como basófilos, plasmócitos e eosinófilos, não foi observada (LAVACH et al., 1977; JÉGOU; LIOTET, 1993; BAKER; LUMSDEN, 2000).

O exame citológico da mucosa conjuntival de felinos domésticos por impressão com papel-filtro mostrou-se viável, sendo indicado para o monitoramento da resposta da mucosa conjuntival à terapia estabelecida.

\section{CONCLUSÕES}

O exame citológico da mucosa conjuntival por impressão com papel de filtro demonstrou riqueza de informações e facilidade de realização, sendo um importante exame complementar no diagnóstico das afecções oculares externas.

O método de impressão utilizado não se mostrou traumático à conjuntiva, evitando qualquer desconforto ao animal, amenizando, assim, a marcada dificuldade encontrada na manipulação dos animais da espécie felina.

O padrão característico normal observado nos felinos domésticos foi de 35 células por campo em média, com predominância da disposição em agrupamentos celulares. As células das camadas intermediárias e superficiais foram as mais freqüentemente observadas. 
Brandão C. V. S.; Minto B. W.; Rocha N. S.; Ranzani J. J. T. - Citologia Conjuntival por impressão em gatos (Felis domestica) - Conjunctival impression cytology in cats (Felis

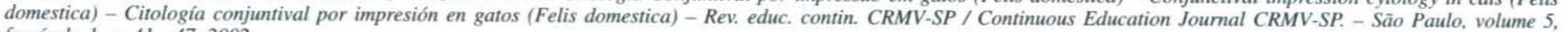

\section{SUMMARY}

Conjunctival citology is an important auxiliary diagnostic method that can be easily used by veterinarians in their practice. The objectives of the present study were to evaluate the feasibility of conjunctival cytology by impression on filter paper and to establish the normal characteristics in the domestic cat. The technique was used in thirty cats without topical anesthesia. The Giemsa and Shorr staining were used to study the citology characteristics. It was found that there is a predominance of epithelial cells in clusters, the cells coming from the intermediate and superficial layers. The collection method proved to be accurate, fast and non-destructive to the conjunctiva, and can be used in the diagnosis and treatment of external eye diseases.

Key words: Cat. Conjunctiva. Cytology. Impression.

\section{RESUMEN}

La citología conjuntival es un importante método de diagnóstico, pues es de sencilla realización por el clínico veterinario. El presente trabajo tiene como objeto estudiar la factibilidad del examen citológico de la mucosa conjuntival por el método de impresión en papel de filtro, al igual que establecer el patrón normal en los felinos domésticos. Se realizó el examen citológico de la mucosa conjuntival por el método de impresión en papel de filtro de 30 animales de la especie felina, sin el uso de anestesia tópica. Las técnicas de coloración usadas fueron Giemsa y Shorr. El patrón normal se caracterizó por predominio de células agrupadas y de células de las capas media y superficial. La técnica de toma del material demostró ser práctica, rápida y proporcionó la obtención de un material de buena calidad. El método de impresión usado no mostró ser traumático para la conjuntiva, disminuyendo la dificultad encontrada para manipular los animales de la especie felina, caracterizándose como un importante examen complementario para el diagnóstico y direccionamiento terapéutico de las afecciones oculares externas.

Palabras clave: Gatos. Conjuntiva. Citología. Impresión.

\section{REFERÊENIAS}

AZEVEDO, M. L. Citologia ocular. 1962. 88 f. Tese (Doutorado) - Faculdade de Medicina, Universidade de São Paulo, São Paulo, 1962.

BAKER, R.; LUMSDEN, J. H. Conjunctiva. In: BAKER, R; LUMSDEN, J. H. Color atlas of cytology of the dog and cat. Missouri: Mosby, 2000. p. 268.

BANKS, W. J. Citologia esfoliativa. In: BANKS, W. J. Histologia veterinária aplicada. 2. ed. São Paulo: Manole, 1992. p. 620629.
GELATT, K. N. Diseases of the conjunctiva. In: NASISSE, M. P. Veterinary ophthalmology. 2. ed. Philadelphia: Lea \& Febiger, 1991.p. 534-535.

JÉGOU, J. P.; LIOTET, S. The benefit of conjunctival scraping cytology in the biological diagnosis of conjunctivitis in the dog and cat. European Journal of Companion Animal Practice, v. 3, p. 83-97, 1993.

LAVACH, J. D.; THRALL, M. A.; BENJAMIN, M. M.; SEVERIN, G. A. Cytology of normal and inflamed conjunctivas 
in dogs and cats. Journal of the American Veterinary Medical Association, v. 170, p. 722-727, 1977.

\section{MALERBA, T. A. Citologia esfoliativa de conjuntiva de cães} (Canis familiaris) e gatos (Felis domestica). 1990. Dissertação (Mestrado) - Faculdade de Medicina Veterinária e Zootecnia, Universidade de São Paulo, São Paulo, 1990.
SLATTER, D. Conjunctiva. In: D. Fundamentals of veterinary ophthalmology. 2. ed. Philadelphia: W.B. Saunders, 1990. p. 204-210.

THATCHER, R. W.; DAROUGAR, S.; JONES, B. R. Conjunctival impression cytology. Archives of Ophthalmology, v. 95, p. 678$681,1977$. 